\title{
MASSIVE OPEN ONLINE COURSES CAMPS: BEFORE AND DURING THE PANDEMIC
}

\author{
Janaina Cardoso \\ Anglo-Germanic Department, Institute of Languages and Literatures, UERJ-Universidade do Estado do \\ Rio de Janeiro (Brazil) \\ CNPq - National Council for Scientific and Technological Development, CNPq Researcher (Brazil)
}

\begin{abstract}
MOOC Camps have been used as a successful blended alternative to more traditional MOOCs (totally online). A "camp" here means "an informal gathering of learners working together to discuss new ideas and concepts" (Sowell, 2019). MOOC Camps combine the positive aspects of MOOCs, such as high-quality of professional development and low cost for participants with the advantages of using the "camps", such as adaptation to the local context and a simpler way of promoting interaction among participants, who consequently feel highly motivated to complete the online course (Cardoso, 2020).

The aim of this presentation is to consider the effects of the physical distance imposed by the COVID-19 pandemic in the MOOC Camps been offered by an extension and research project developed at a public university in Rio de Janeiro, Brazil (CEALD/UERJ) in partnership with the American Government (RELO-Brazil) since 2019. The main objectives of these MOOC camps are: (a) to promote language and methodology development; and (b) to build stronger communities of teachers and teachers-to-be, by giving them the opportunity of sharing their experiences. However, in 2020, due to the pandemic, the camp had to be adapted to a remote mode, using a web-conference platform. Therefore, this action-research study compares and contrasts the MOOC Camp participants' feedback given before the pandemic with their responses to the activities developed during the pandemic. In this way, the idea is to understand how the adaptations we were forced to make have influenced the development of the camps and possibly affected participants' interest.

The discussion considers some of the advantages and drawbacks of adopting the remote mode for the camps, and a better understanding of some theoretical concepts, such as: blended learning (Gruba et al., 2016); blended MOOCs (Albó et al., 2015; Orsini-Jones, 2018, 2019), online interaction (Silva, 2014), and education in the pandemic context (Liberali, 2020).
\end{abstract}

Keywords: MOOC camps, pandemic context, online interaction, blended learning, remote teaching.

\section{Introduction}

Since 2019, we have used Massive Open Online Courses Camps (MOOC Camps) for language teacher development as an alternative to the regular MOOCs. The term "camp" in this context is defined as "an informal gathering of learners working together to discuss new ideas and concepts" (Sowell, 2019). These face-to-face facilitated sessions were offered by a research the extension project developed at a public university in Rio de Janeiro, Brazil (CEALD/UERJ). In fact, UERJ was the first university to organize MOOC Camps in partnership with the American Embassy in Brazil (RELO-Brazil). The American Government sponsored the MOOCs and the university was responsible for the camps.

MOOC Camps differ from other MOOCs because it allows more interaction between participants (Silva, 2014). Participants (including the facilitators) work together, exchanging work experience, discussing topics introduced in the online course, preparing lesson plans and developing teaching activities. However, it also differs from many other kinds of blended MOOCs (bMOOCs) (Albó, 2015; Orsini-Jones, 2018, 2019) because it is not a way of integrating MOOCs to the traditional curriculum, but to offer support to the online course. MOOC Camps have been used as continuous education and, consequently, participants have no formal obligation to take them.

MOOC Camps have combined the positive aspects of MOOCs such as high-quality of professional development and low cost for participants with the advantages of using the "camps", such as adaptation to the local context and a simpler way of promoting interaction among participants, who 
consequently feel highly motivated to complete the online course (Cardoso, 2020). The main objectives of CEALD MOOC camps are: (a) to promote language and methodology development; and (b) to build stronger communities of teachers and teachers-to-be, by giving them the opportunity of sharing their experiences.

The results of this previous studies (Cardoso, 2020) showed that CEALD MOOC Camps were successful. According to the participants' feedback, they have developed their methodology awareness and improved their knowledge of the English language. Not only did they consider the face-to-face facilitated sessions useful, but they believed that these sessions helped keeping them more interested in the online course. However, in 2020, with the Covid-19 pandemic, we had to adopt a remote mode. The in-person gathering were substituted by synchronous meeting using a web-conference platform (RNP - a Brazilian open platform).

Therefore, this study presents the findings of this second cycle of a participatory action research project. The main objective is to discuss the effects of the physical distance imposed by the COVID-19 pandemic in these MOOC Camps. In this phase, the research compares and contrasts the MOOC Camps participants' feedback given before the pandemic with their responses to the activities developed during the pandemic, in order to understand how the adaptations we were forced to make have influenced the development of the camps and possibly affected participants' interest.

We believe that this discussion may help in the development of new versions of the MOOC Camps in the future.

\section{Research background}

As mentioned before, the present study is part of a bigger research and extension project called CEALD, which in Portuguese stands for "Collaboration, Learning Strategies and Digital Literacies". The aim of the project is to provide opportunities for language and methodological development for teachers adopting a reflective and critical approach (Cardoso, 2018). The project is based on three main concepts: equity, resistance and collaboration. The first objective was "to help learners who have lower level of English than their classmates succeed in their ELT graduate course" (Mateus, Miller \& Cardoso, 2019), but as time went by, we noticed that there were teachers who also needed language improvement and/or methodology update but could not afford paid courses or did not have time for formal post-graduate education. MOOC Camps which focused on teaching methodology awareness seemed a good option as teachers and university students (teacher-to-be) from different backgrounds and at different levels of English could work together, collaboratively discussing new teaching and learning approaches, designing activities and exchanging experiences, fostering Silva (2014)'s concept of "interactive classroom". Another positive point is that the online courses help participants develop their digital literacies (Pegrum \& Cardoso, 2019), and to adopt a more positive view towards using technology in the classroom in a creative and critical way. For all these reasons, the MOOC Camps have been used as one of the intervention activities of the research project. There are other intervention activities, such as events, lectures, research groups, individual assistant, but in the present study we will focus on the camps.

In 2019, we offered three MOOC Camps: Teaching Grammar Communicatively, Integrating Critical Thinking Skills into the Exploration of Culture in the EFL Setting and Teaching English to Young Learners. For each camp, we had from 20 to 30 participants (divided in two groups), about 83 participants altogether in that year. Our plans were to offer at least two camps in 2020, but due to the Covid-19, we were able to offer only one, by the end of the year when the classes restarted (September 23 - October 28), with a one-hour synchronous session a week. As Liberali (2020) mentions, with the pandemic we had to rethink our priorities as educators. The most important aim was to survive, and the pandemic showed that many of us was substantially vulnerable not just in relation to health conditions, but to basic survival needs. Liberali mentions that "necro-politics" (which deals with the decision of who will survive and who will die) led also to "necro-education" (which deals with the decision of who will be able to study who will not), but we could not surrender. Emergency remote education has seemed to be the only option, but for some of the learners and teachers this was not an option at all, for lack of equipment or internet connection, unhealthy conditions (including lack of concentration), and/or unemployment (which in many cases led to hunger). Most teachers were not prepared to adopt this new kind of teaching, but we had to learn fast. The most heard term was "adaptation". But how to be flexible and creative in such conditions? Collaboration became one of the most important alternatives. We had to share ideas to find solutions to our common problems. Autonomy was transformed into interdependence.

In our case, with adaptation in the modality and collaboration of colleagues and university students who worked as a team of facilitators we were able to offer the MOOC Camp TESOL Methodology. 


\section{Research methodology}

As already mentioned, this study is a second cycle of a participatory action research project. The first phase we considered the usefulness of the face-to-face facilitated sessions. We found out that participants who finished the camp had a very positive perspective in relation to the online course and the in-person facilitated sessions. Besides, they felt highly motivated in taking other MOOC Camps (Cardoso, 2020). Following Kemmis \& Wilkson (2011) and Thiollent (2011) and steps of the action research cycle of our project were defined as can be seen in Figure 1:

Figure 1. CEALD Project Action Research Cycle (Cardoso, 2018, 2020).

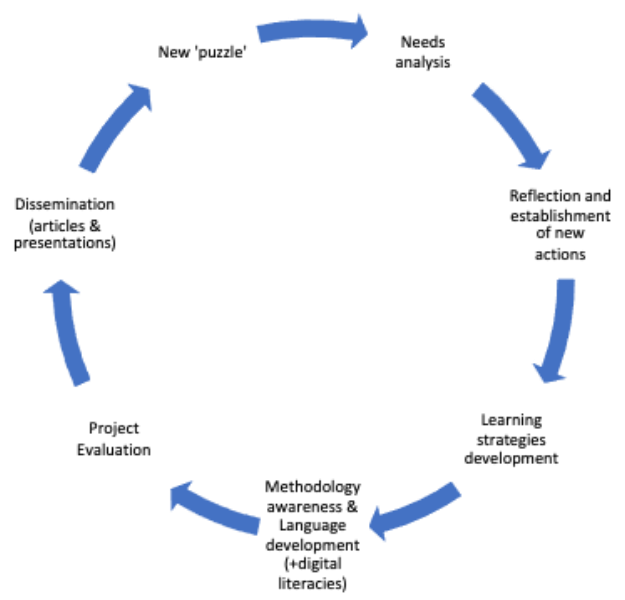

In the first cycle, we had already evaluated the project, disseminated ideas (in conferences and articles), but suddenly we had a new 'puzzle' (Allwright 2002, 2003 apud Cardoso 2020), which was the adaptations we had to do because of the pandemic. After considering the problems and much discussion, we (group of facilitators) decided to use virtual meetings, during the sessions again we discussed teaching and learning strategies and tried to improve their language use and digital literacy through methodology awareness. Now we are using their feedback to evaluate the process and disseminate the findings. This discussion will help decide about the project next steps.

\subsection{Research participants}

In the previous versions of CEALD MOOC Camps, about two-third of the participants were English language teachers and one-third were university students (future teachers). In each group, there were at least four facilitators and 10 participants. We accepted 15 participants for each group (30 altogether), but only 22 answered the feedback questionnaire. Therefore, they will be considered our main research participants. The participants were between 20 and 50 years old. In each group, there were always four or five facilitators. In group one, the facilitators were 2 monitors (undergraduate) and 3 professors, while in group two, there were 1 monitor (undergraduate), 1 teacher (Master degree student and part-time university teacher) and 2 professors. The university teachers were between 40 and 59 years old. As for the monitors, they were in their 20s. All participants (including the facilitators) are Brazilian, being Portuguese our first language, but we only spoke in English during the synchronous virtual meeting. In the WhatsApp group, we normally interacted in Portuguese, but exchanged texts and videos in English.

\subsection{Research questions}

The main aim of the research is to understand how the adaptations we were forced to make because of the Covid-19 pandemic have influenced the development of the camps and possibly affected participants' interest. Therefore, our main research questions are the following:

RQ1: How has the pandemic forced a change in the MOOC Camps?

RQ2: What were the participants' responses? In which ways do they differ from previous ones?

RQ3: How may this experience affect our future plans (taking into consideration not just 2021, but afterwards)? What can be done in the future?

To answer these questions, besides comparing and contrasting the participants' feedback before and during the pandemic, we will also use facilitators' opinions. 


\subsection{Instruments}

In CEALD research project, we generally use three kinds of instruments: questionnaires, answered by the intervention activities participants; diaries used by facilitators and interviews with invited participants and facilitators. For this specific cycle of the participatory action research, we intend to use a questionnaire suggested by the RELO Office (Sowell, 2019) and adapted by us to be answered using Google Forms. It consists of nine questions, in the format of statements to be confirmed or denied. The topics being considered are the following: methodology awareness; English language improvement; facilitated sessions usefulness; completion of the course online; interest in taking another MOOC Camp; preferred mode (facilitated and/or online course). The last item of the questionnaire is an open question asking for other comments about the MOOC Camp. Participants do not have the obligation of answering the questionnaires and none of them are signed. The answers are compiled after each course, and the offering of other courses are based on these responses and the availability of the courses they are interested in taking.

Informal interviews with facilitators will also be used in an attempt to answer the first and the last questions.

\section{First findings and discussion}

30 (future) teachers enrolled to the camp, but only 22 received the certificates (attended more than $75 \%$ synchronous meetings). The same number answered the feedback questionnaire. The dropout rate was $27 \%$ (if we consider only the (future)teachers) and consequently the rate of retention (73\%) was very similar to the average results of the face-to-face camps (74\%) (Cardoso, 2020).

If we consider the answers to the questionnaire, they were very similar to the ones collected in the first cycle. For example, in relation to methodology awareness, most of the participants (86\%) of the participants strongly agreed that "because of the course they now know more about the TESOL methodology", in other courses $84 \%$ strongly agreed with this first statement. The same happened in relation to facilitated session, in the virtual interaction group, $90.9 \%$ strongly agreed that they were useful and $9.1 \%$ agreed. In the previous face-to-face (F2F) groups, again most participants (84\%) strongly agreed, $13 \%$ somewhat agreed and $2 \%$ agreed. The majority of the participants want to take a MOOC Camp in the future (virtual 100\% and F2F 94\%). Another very positive aspect which was confirmed in both cases is that most participants followed both the online course and facilitated sessions (virtual $96 \%$ and $\mathrm{F} 2 \mathrm{~F}$ 95\%).

The main difference may be found in the answers to two questions: (2) "Because of the course, my English improved" and (6) "I completed all the online coursework." See the table below:

Table 1. Feedback questionnaires - Contrasting F2F and Virtual learners'answers - Questions 2 and 5.

\begin{tabular}{|l|c|c|c|c|c|}
\hline \multicolumn{7}{|c|}{ (2) Because of the course, my English improved. } \\
\hline F2F & $\begin{array}{c}\text { Strongly } \\
\text { agree }\end{array}$ & $\begin{array}{c}\text { Somewhat } \\
\text { agree }\end{array}$ & Agree & $\begin{array}{c}\text { Somewhat } \\
\text { disagree }\end{array}$ & Disagree \\
\hline Virtual & $24.0 \%$ & $40.0 \%$ & $31.0 \%$ & $2.0 \%$ & $3.0 \%$ \\
\hline \multicolumn{7}{|c|}{$40.9 \%$} & $31.8 \%$ & $27.3 \%$ & $0,0 \%$ & $0.0 \%$ \\
\hline F2F & Yes I completed all the online coursework. & Not yet \\
\hline Virtual & $66 \%$ & No & No answers & $8 \%$ & $68 \%$ \\
\hline
\end{tabular}

Although learners from both groups agreed that because of the course their English improved, the learners from the virtual group were much more positive than the other groups, as $40.9 \%$ of them strongly agree and only $24 \%$ from the F2F strongly agreed (Table 1).

The biggest difference has to do with the completion of the online course (Table 1). When the camp was F2F most learners finished the course before the last facilitated session. As for the virtual camp, only $32 \%$ completed the online course before the last facilitated session and most of them answered they had not finished yet. However, we have to consider that in the previous questionnaires there was not the option "Not yet", so most learners who had not finish the course answered "No" and only a few included a third option ("Not yet"), showing that they were interested in finishing it. Anyway, the results show that we must be more careful in relation to the completion of the online course the next time. 


\section{Conclusions and future work}

The research questions are partially answered. As the participants from previous MOOC Camps, the one who took the virtual version believed the facilitated sessions were useful for methodology awareness and language development. However, the number of participants who finished the online course was much lower than when they attended face-to-face sessions. In a way, it may be related to the previous phase of the participatory action research, in which we advocated the importance of the face-to- face interaction to foster more interest in the online course. In fact, that was the reason for creating the camps.

The next step is to informally interview the facilitators to help answer the other research questions. Another instrument that may help our discussion is the blended language program evaluation (Gruba et al, 2016). For this evaluation, they take into consideration different criteria, such as: purpose, appropriateness, multimodality and sustainability (Gruba et al., 2016, p. 29-32).

Besides, for 2021, three MOOC Camps are being planned: Assessment of English Language Learners (May/June); TESOL Methodology (July/August), Integrating Critical Thinking Skills into the Exploration of Culture in EFL Setting (September/October).

\section{References}

Albó, L., Hernandez-Leo, D. \& Oliver, M. (2015). Blended MOOCs: university teachers' perspective. Trends in Digital Education. Selected papers from EC-TEL 2015 Workshops CHANGE, WAPLA, and HybridEd. Retrieved October 10, 2020 from http://ceur-ws.org/Vol1599/2HybridEd_2015.pdf

Cardoso, J. (2018). The challenge of fostering equity in a TESOL graduate course: a participatory action research project. In M. Carmo (Ed.), Education and New Developments 2018 (317-321). Lisbon: inScience Press.

Cardoso, J. (2020). Massive Open Online Course Camps: Promoting effective blended courses for language teachers' development. The International Journal of Humanities Education. Common Ground. (in press)

Gruba, P., Cárdena-Claros, M., Suvorov, R. \& Rick, K. (2016). Blended language program evaluation. London: Palgrave Macmillan.

Kemmis, S. \& Wilkinson, M. (2011). A pesquisa-ação participativa e o estudo da prática. In J. E. Diniz-Pereira \& K. M. Zeichner (Eds.), A pesquisa ação na formação e no trabalho docente (39-60). Belo Horizonte: Autêntica.

Liberali, F. Construir o inédito viável em meio a crise do coronavírus - lições que aprendemos, vivemos e propomos. In F. Liberali, V. Fuga, U. Diegues \& M. Carvalho (Eds). Educação em tempos de pandemia: brincando com um mundo possível. Campinas: Pontes.

Mateus, E. Miller, I. Cardoso, J. (2019). Teaching to learn: ways of experiencing the practicum, teacher education and development. D.E.L.T.A. v. 35 N. 3. Retrieved October 10, 2020, from https://doi.org/10.1590/1678-460x2019350303

Orsini-Jones, M. \& Carrascosa, A. C. (2019). BMELTET - Blending MOOCs into English language teacher education with telecollaboration. In A. Plutino, K. Borthwick \& E. Corradini (Eds.) New educational landscapes: innovative perspectives in language learning and technology (pp. 1-17). Research-publishing.net. Retrieved October 15 from https://www.researchgate.net/publication/334374205_BMELTET_-

Blending_MOOCs_into_English_language teacher_education_with telecollaboration

Orsini-Jones, M. Conde, B., Borthwick, K., Zou, B., Ma, W. (2018). B-MELTT: Blending MOOCs for English Language Teacher Training. ELT Research Papers 18.02. London: British Council. Retrieved October 10, 2020 from https:/www.teachingenglish.org.uk/article/b-meltt-blendingmoocs-english-language-teacher-training

Pegrum, M. \& Cardoso, J. (2019). Digital literacies in language education: Janaina Cardoso interviews Mark Pegrum. Matraga, v. 26, n. 47. p.462-469.

Silva, M. (2014). Sala de aula interativa. São Paulo: Loyola.

Sowell, J. (2019). MOOC Camp Facilitation Guide. Washington, DC: Bureau of Educational and Cultural Affairs, United States Department of State.

Thiollent, M. (2011). Metodologia da pesquisa-ação. São Paulo: Cortez. 